\title{
PHẪU THUÂTT NộI SOI LỒNG NGỰC ĐÎ̀̂U TRI TRÀN KHÍ MÀNG PHỔI TỰ PHÁT NGUYÊN PHÁT: KẾT QUẢ ĐIỀU TRI TẠI BỆNH VIỆN QUÂN Y 103
}

\section{TÓM TẮT}

Mục tiêu: Đánh giá kết quả phẫu thuật nội soi lồng ngực điều trị tràn khí màng phổi tự phát nguyên phát. Đối tượng và phương pháp nghiên cứu: Từ tháng 01/2016 đến 04/2021, 77 bệnh nhân tràn khí màng phổi tự phát nguyên phát được phẫu thuật nội soi lồng ngực tại Bệnh viện Quân y 103. Kết quả: Thời gian phẫu thuật trung bình $56,1 \pm 6,6$ phút. Ngày nằm viện sau mổ $7,2 \pm 1,1$ ngày. Tỷ lệ biến chứng sau mổ 2,6\%. Kết luận: Phẫu thuật nội soi lồng ngực an toàn và hiệu quả trong điều trị tràn khí màng phổi tự phát nguyển phát. Bệnh nhân hồi phục nhanh, thời gian nằm viện ngắn, ítbiến chứng sau mổ.

Tư khóa: Tràn khí màng phổi tự phát nguyên phát, phẫu thuật nội soi lồng ngực.

\section{SUMMARY}

\section{VIDEO - ASSISTED THORACOSCOPIC SURGERYFOR PRIMARY SPONTANEOUS PNEUMOTHORAX: THE RESULTS AT MILITARY HOSPITAL 103}

Objectives: To evaluate the results of video assisted thoracoscopic surgery (VATS) for primary spontaneous pneumothorax. Subjects and methods: From January 2016 to April 2021, 77 patients with primary spontaneous pneumothorax underwent VATS at Military Hospital 103. Results: The average surgical time was $56.1 \pm 6.6$ minutes. Postoperative hospital stay was7.2 \pm 1.1 days. The rate of postoperative complications was $2.6 \%$. Conclusions: VATS is safe and effective in the treatment of primary spontaneous pneumothorax. The patient recovered quickly, the hospital stay was short, and therate of postoperative complications was low.

Keywords: Primary spontaneous pneumothorax, video - assisted thoracoscopic surgery.

\section{I. ĐẶT VẤN ĐỀ}

Tràn khí màng phổi tự phát nguyên phát (TKMPTPNP) là bệnh lý cấp cứu thường gặp, xảy ra ở người trẻ tuổi, không có bệnh lý phổi, không do chấn thương hay can thiệp vào lồng ngực. Tỷ lệmắc bệnh khoảng 8 - 12/100.000 đối với nam và 2 - 3/100.000 đối với nữ [1], [2].

TKMPTPNP có thể điều trị bảo tồn, chủ yếu là đặt dẫn lưu khoang màng phổi, được thực hiện ở khoảng $50 \%$ số bệnh nhân[3], tuy nhiên có

*Bệnh viện 103 - Học viện Quân y.

Chịu trách nhiệm chính: Nguyễn Văn Hoàng

Email: dr.nguyenhoanghvqy@gmail.com

Ngày nhận bài: 25/5/2021

Ngày phản biên khoa hoc: 23/6/2021

Ngày duyệt bài: 21/7/2021 những trường hợp đòi hỏi phải phẫu thuật, mục đích làm hết khí trong khoang màng phổi giúp phổi nở lại và ngăn ngừa tái phát. Trước đây phẫu thuật mở ngực điều trị TKMPTPNP được áp dụng cho kết quả tốt nhưng đây là phẫu thuật xẩm lấn nhiều và tỷ lệ tai biến, biến chứng cao[4]. Hiện nay phẩu thuật nội soi lồng ngực (PTNSLN) điều trị TKMPTPNP đã cho thây có nhiều ưu điểm hơn và đang được áp dụng thường quy tại Khoa Phẫu thuật Lồng ngực-Bệnh viện Quân y 103. Đây là báo cáo ghi nhận sự tổng kết một cách có hệ thống về PTNSLN điều trị TKMPTPNP của chúng tôi.

II. ĐỐI TƯỢNG VÀ PHƯƠNG PHÁP NGHIÊN CỨU

2.1. Đối tượng nghiên cứu: Gồm 77 bênh nhân TKMPTPNP được PTNSLN tai Khoa Phẫu thuật Lồng ngực - Bệnh viện Quân y 103, từ tháng 01/2016-04/2021.

- Tiêu chuẩn lưa chon[3]: Bênh nhân được chẩn đoán TKMPTPNP có một trong các tiểu chuẩn sau:

+ Rò khí kéo dài (> 5 ngày) sau đặt dẫn lưu màng phổi.

+ Tái phát sau điều trị bảo tồn.

+ Phát hiện bóng kén khí trên phim chụp cắt lớp vi tính lồng ngực.

- Tiêu chuân loại trừ[3]:

+ Tiền sử phẫu thuật phổi cùng bên.

+ Bệnh nhân không đủ điều kiện hoặc không đồng ý phẫu thuật nội soi.

\subsection{Phương pháp nghiên cứu}

2.2.1.Phương pháp nghiên cứu: Hồi cứu, mô tả cắt ngang.

2.2.2. PTNSLN điêu trị TKMPTPNP

- Vô cảm: nội khí quản hai nòng.

- Tư thế: nghiêng sang bên đối diện với bên tổn thương $90^{\circ}$.

- Tư thế phẫu thuật viên: đứng bên phải bệnh nhân.

- Đường tiếp cận: sử dụng 03 trocar kinh điển.

- Xác định tổn thương (bóng kén khí, lỗ rò khí...), tuỳ theo tổn thương mà xử trí bằng gây dính, cắt phổi hình chêm chỗ có tổn thương bằng $1-2$ stapler $60 \mathrm{~mm}$. Lấy bệnh phẩm bằng túi đựng bệnh phẩm dưới sự quan sát của camera.

- Kiểm tra lại tình trạng rò khí, gây dính màng phổi bằng làm xước lá thành và betadine 10\% đậm đặc. 
- Kiểm tra lại vùng mổ, đặt 1-2 dẫn lưu khoang màng phổi.

- Bệnh nhân được rút ống nôi khí quản ngay tại phòng mổ, chăm sóc hậu phẩu tại Khoa phẫu thuật Lồng ngực - Bệnh viện Quân y 103.

2.2.3. Các chỉ tiều nghiên cứu

- Một số đặc điểm chung: tuổi, giới, lâm sàng, mức độ tràn khí, vị trí tổn thương.

- Đánh giá trong mổ: đặc điểm tổn thương trong mổ, vị trí bóng khí, thời gian phẫu thuật, thời gian điều trị sau mổ, thời gian nằm viện.

- Đánh giá sau mổ: biến chứng.

\subsection{Thu thập và xử lý số liệu}

- Số liệu được ghi nhận vào mẫu bệnh án nghiên cứu cho từng bệnh nhân và xử lý bằng phần mềm SPSS 22.0.

- Sử dụng phép kiểm $T$ để so sánh hai giá trị trung bình, phép kiểm $\chi^{2}$ (khi bình phương) để so sánh hai tỳ lệ.

Bảng 2. Đặc điểm tổn thương và cách xử trí

\begin{tabular}{|c|c|c|c|c|}
\hline Phân loại & Tốn thương & Cách xử trí & Số bệnh nhân & Tỷ lệ \% \\
\hline Nhóm i & Không phát hiện tốn thương & Gây dính màng phối. & 5 & 6,5 \\
\hline Nhóm 2 & $\begin{array}{c}\text { Dính màng phối do võ̃ bóng } \\
\text { khí }\end{array}$ & $\begin{array}{c}\text { Gõ dính + } \\
\text { Gây dính màng phổi. }\end{array}$ & 1 & 1,3 \\
\hline Nhóm 3 & Bóng khí $<2 \mathrm{~cm}$ & $\begin{array}{l}\text { Cắt bóng khí bằng stapler + } \\
\text { Gây dính màng phổi. }\end{array}$ & 27 & 35,1 \\
\hline Nhóm 4 & Bóng khí $\geq 2 \mathrm{~cm}$ & $\begin{array}{l}\text { Cắt bóng khí bằng stapler + } \\
\text { Gây dính màng phổi. }\end{array}$ & 44 & 57,1 \\
\hline \multicolumn{3}{|c|}{ Tống } & 77 & 100 \\
\hline
\end{tabular}

*Chúng tôi phân loại tốn thương theo Vanderschueren, chia thành 4 nhóm: không phát hiện tốn thương $(6,5 \%)$, dính màng phổi do vỡ bóng khí $(1,3 \%)$, bóng khí $<2 \mathrm{~cm}(35,1 \%)$, bóng khí $\geq 2 \mathrm{~cm}$ $(57,1 \%)$.

Bảng 3. Đặc điểm bóng kén khí trong mổ

\begin{tabular}{|c|c|c|c|}
\hline \multicolumn{2}{|c|}{ Vị trí bóng kén khí } & $\begin{array}{c}\text { Số bệ̂nh } \\
\text { nhẩn }\end{array}$ & $\begin{array}{c}\text { Tỷ lệ } \\
\text { \%o }\end{array}$ \\
\hline \multirow{2}{*}{$\begin{array}{c}\text { Phổi phải } \\
(n=39)\end{array}$} & Thùy trên & 37 & 94,8 \\
\cline { 2 - 4 } & Thùy giữa & 1 & 2,6 \\
\cline { 2 - 4 } & Thùy dưới & 1 & 2,6 \\
\hline \multirow{2}{*}{$\begin{array}{c}\text { Phổi trái } \\
\text { ( } \mathrm{n}=32)\end{array}$} & Thùy trên & 30 & 93,8 \\
\cline { 2 - 4 } & Thùy dưới & 2 & 6,2 \\
\hline
\end{tabular}

*Đa số bóng kén khí nằm ở thùy trên phổi phải hoặc phổi trái. Trường hợp tổn thương phổi phải, vị trí bóng kén khí thùy trên gặp ở $94,8 \%$, thùy giữa và thùy dưới đều là $2,6 \%$. Trường hợp tổn thương phổi trái, vị trí bóng kén khí thùy trền gặp ở 93,8\%, thùy dưới gặp ở 6,2\% bệnh nhân.

Bảng 4. Kêt quả phẩu thuật

\begin{tabular}{|c|c|}
\hline Chỉ tiêu & $\begin{array}{c}\text { Trung bình } \\
(X \pm S D)\end{array}$ \\
\hline Thời gian phâu thuật (phút) & $56,1 \pm 6,6$ \\
\hline $\begin{array}{c}\text { Thời gian điêu trị sau mô } \\
\text { (ngày) }\end{array}$ & $7,2 \pm 1,1$ \\
\hline Thời gian nămm viện (ngày) & $9,6 \pm 2,5$ \\
\hline
\end{tabular}

\section{KẾT QUẢ NGHIÊN CỨU}

\subsection{Một số đặc điểm chung}

*Tuổi trung bình của bệnh nhân $32,3 \pm 10,1$; thấp nhất là 17 tuổi, cao nhất là 58 tuổi, chủ yếu bệnh nhân dưới 40 tuổi (80,5\%). Đa số bệnh nhân là nam giới chiếm $93,5 \%$, nữ giới chiếm $6,5 \%$.

Bảng 1. Triệu chứng lâm sàng

\begin{tabular}{|c|c|c|}
\hline Triệu chứng & Số bệnh nhân & Tỷ lệ \% \\
\hline Đau ngực & 76 & 98,7 \\
\hline Khó thở & 72 & 93,5 \\
\hline Ho khan & 12 & 15,6 \\
\hline
\end{tabular}

*Đau ngực và khó thở gặp ở đa số các trường hợp: $98,7 \%$ và $93,5 \%$.

*Đa số bệnh nhân tràn khí mức độ vừa $(44,2 \%)$ và nặng $(49,3 \%)$, chỉ có $6,5 \%$ bệnh nhân tràn khí mức độ nhẹ.

*Tràn khí màng phổi tương đương nhau ở bên phải $(53,2 \%)$ và bên trái $(46,8 \%)$.

\section{2. Đánh giá trong mổ}


dưới 40 tuổi $(80,5 \%)$. Kết quả nghiên cứu cũng tương tự trong nghiên cứu của Puri và CS [5] trên 110 bệnh nhân tràn khí màng phổi tự phát nguyên phát có tuổi trung bình là 27,6 (từ 9 đến 68 tuổi); hay nghiên cứu của Aljehani và CS [6] trên 151 bệnh nhân tràn khí màng phổi tự phát nguyên phát cho thấy tuổi trung bình là $24 \pm 6$ (từ 13 đến 49 tuổi).

Trong nghiên cứu của chúng tôi, đa số bệnh nhân là nam giới chiếm $93,5 \%$, nữ giới chiếm $6,5 \%$. Kết quả nghiên cứu của chúng tôi cũng phù hợp nghiên cứu của Chikaishi và CS [7] cho thây nam giới $91,3 \%$, nữ giới $8,7 \%$; Dogusoy và CS [4] nhận thấy nam giới 90,8\%, nữ giới 9,2\%; Aljehani và CS [6] nhận thây tỷ lệ nam giới là $98,7 \%$, nữ giới $1,3 \%$;trong khi Puri và CS [5] nhận thấy tỷ lệ nam giới là $78,2 \%$ và nữ giới là $21,8 \%$.

*Đặc điểm lâm sàng và mức độ tràn khí. Nghiên cứu của chúng tôi nhận thấy đau ngực và khó thở gặp ở đa số các trường hợp: 98,7\% bệnh nhân có biểu hiện đau ngực và $93,5 \%$ bệnh nhân có biểu hiện khó thở, đầy cũng là các triệu chứng chính khiến bệnh nhân phải đến viện. Ngoài ra ho khan cũng ghi nhận ở 15,6\% các trường hợp.

Hình ảnh $X$ quang ngực quy ước có giá trị cao trong chẩn đoán ban đâu và theo dõi sau phẫu thuật TKMPTPNP. Chúng tôi phân loại mức độ tràn khí trên phim $X$ quang ngực theo Kircher: mức độ nhẹ < $20 \%$, mức độ vừa $20 \%-50 \%$ và mức độ nặng $>50 \%$. Nghiển cứu của chúng tôi nhận thây đa số bệnh nhân tràn khí mức độ vừa $(44,2 \%)$ và nặng $(49,3 \%)$, chỉ có $6,5 \%$ bệnh nhân tràn khí mức độ nhẹ. Kết quả tương tự như trong nghiên cứu của Chikaishi và CS [7] trên 149 bệnh nhân TKMPTPNP cho thấy mức độ nhe $(9,4 \%)$, chủ yếu mức độ vừa $(60,4 \%)$ và mức độ nặng nặng (30,2\%).

Ngoài ra chúng tôi cũng ghi nhận 6 trường hợp tràn khí màng phổi mức độ nặng kèm theo máu đông màng phổi do đứt dây chằng đỉnh phổi, trong đó 4 trường hợp tổn thương được tìm thấy là lỗ rò khí nằm ở thùy trên phổi trái và 2 trường hợp không tìm thây tổn thương trong mổ. Các trường hợp này đều được lấy máu đông trong khoang màng phổi qua phẫu thuật nội soi và làm sạch khoang màng phổi, với 4 trường hợp tìm thấy tổn thương chúng tôi tiến hành cắt lỗ rò khí bằng stapler sau đó gây dính màng phổi bằng cách làm xước lá thành màng phổi và bơm dung dịch betadine đậm đặc vào khoang màng phổi; 2 trường hợp không tìm thây tổn thương chúng tôi chỉ tiến hành gây dính màng phổi. Kểt quả sau mổ cho thấy không có biến chứng ở cả
6 trường hợp này.

Trong nghiên cứu của chúng tôi, tràn khí màng phổi bên phải có 41 bệnh nhân (chiếm $53,2 \%$ ), tràn khí màng phổi bên trái có 36 bệnh nhân (chiếm 46,8\%), không ghi nhận trường hợp nào tràn khí màng phổi đồng thời hai bên. Kết quả nghiên cứu của Puri và CS [5] cho thây tràn khí màng phổi bên phải chiếm $43,6 \%$, bên trái chiếm $52,7 \%$, hai bên 3,6\%; nghiên cứu của Yoshikawa và CS [8] cho thấy tràn khí màng phổi bên phải chiếm $46,1 \%$, bên trái chiếm $53,9 \%$.

\section{2. Đánh giá trong mổ}

*Đặc điểmtổn thương và xử trí. Nghiên cứu của chúng tôi phân loại tổn thương tràn khí màng phổi tự phát nguyên phát theo Vanderschueren, chia thành 4 nhóm: không phát hiện tổn thương $(6,5 \%)$, dính màng phổi do võ bóng khí $(1,3 \%)$, bóng khí < $2 \mathrm{~cm}(35,1 \%)$, bóng khí $\geq 2 \mathrm{~cm}(57,1 \%)$. Kết quả nghiên cứu của Puri và CS [5] trên 110 bệnh nhân tràn khí màng phổi tự phát nguyên phát cho thấy không phát hiện tổn thương chiếm $5,5 \%$, dính màng phổi do võ bóng khí chiếm $1,8 \%$, bóng khí $<2 \mathrm{~cm}$ chiếm $61,8 \%$ và bóng khí $\geq 2 \mathrm{~cm}$ chiếm $30,9 \%$.

Trong nghiên cứu của chúng tôi, đa số bóng kén khí nằm ở thùy trên phổi phải hoặc phổi trái, tương ứng là $94,8 \%$ và $93,8 \%$.

Hầu hết trường hợp chúng tôi lựa chọn xử trí tổn thương bóng kén khí hay lố rò khí bằng stapler và gây dính; các trường hợp khác chúng tôi tiến hành gây dính bằng cách làm xước lá thành màng phổi kết hợp với sử dụng betadine đậm đặc.

*Kểt quả phẫu thuật. Thời gian phẫu thuật trung bình trong nghiên cứu của chúng tôi là $56,1 \pm 6,6$ phút, thời gian điều trị sau mổ là 7,2 $\pm 1,1$ ngày và thời gian nằm viện trung bình là $9,6 \pm 2,5$ ngày. Nghiên cứu của Yoshikawa và CS [8] cho thấy thời gian phẫu thuật trung bình là $38,1 \pm 17,5$ phút, thời gian nằm viện sau mô là $2,6 \pm 0,8$ ngày. Thời gian phẫu thuật, thời gian điều trị sau mổ cũng như thời gian nằm viện trung bình ghi nhận có sự khác nhau giữa các trung tâm có thể do sự khác nhau về trang thiết bị tại cơ sở phẫu thuật, thời gian để dẫn lưu màng phổi sau phẫu thuật cũng như trình độ phẫu thuật viên thực hiện phẫu thuật.

4.3. Đánh giá sau mổ. Nghiên cứu của chúng tôi nhận thấy có 2,6\% trường hợp rò khí kéo dài (rò khí trên 5 ngày) sau mổ, không ghi nhận trường hợp nào tràn máu màng phổi, máu đông màng phổi, viêm phổi hay mủ màng phổi sau mổ. Hai trường hợp này chúng tôi đều phải phẫu thuật lại, kiểm tra và xử lý lại tổn thương. 
Kết quả nghiên cứu của chúng tôi cũng phù hợp kết quả nghiên cứu của Puri và CS[5] với tỷ lệ biến chứng chung là $3,6 \%$ hay trong nghiên cứu của Yoshikawa và CS [8] cho thây tỷ lệ biến chứng là $2,8 \%$.

\section{KẾT LUẬN}

Phẫu thuật nội soi lồng ngực điều trị tràn khí màng phổi tự phát nguyên phát là phương pháp an toàn và hiệu quả, với thời gian điều trị ngắn, khả năng phục hồi nhanh, tỷ lệ tai biến, biến chứng thấp.

\section{TÀI LIÊU THAM KHẢO}

1. Hallifax Rob J, Goldacre Raph, Landray Martin J, et al. (2018), "Trends in the incidence and recurrence of inpatient-treated spontaneous pneumothorax, 1968-2016", Jama, 320(14), 1471-1480.

2. Olesen Winnie Hedevang, Titlestad Ingrid Louise, Andersen Poul Erik, et al. (2019), "Incidence of primary spontaneous pneumothorax: a validated, register-based nationwide study", ERJ open research, 5(2), 00022-2019.

3. MacDuff Andrew, Arnold Anthony, Harvey John (2010), "Management of spontaneous pneumothorax: British Thoracic Society pleural disease guideline 2010", Thorax, 65(Suppl 2), ii18-ii31.

4. Doğusoy Ilgaz, Yıldırım Mehmet, Ustaalioğlu Recep, et al. (2018), "A comparison of axillary thoracotomy versus video-assisted thoracoscopic surgery in the surgical treatment of primary spontaneous pneumothorax", Turk gogus kalp damar cerrahisi dergisi, 26(1), 132-137.

5. Puri Harsh Vardhan, Asaf Belal Bin, Pulle Mohan Venkatesh, et al. (2021), "Video-assisted thoracoscopic surgery management of primary spontaneous pneumothorax: Results in 110 consecutive cases", Lung India : official organ of Indian Chest Society, 38(1), 36-40.

6. Aljehani Yasser Mahir, Almajid Feras Mohammed, Niaz Rabia C., et al. (2018), "Management of Primary Spontaneous Pneumothorax: A Single-center Experience", Saudi journal of medicine \& medical sciences, 6(2), 100-103.

7. Chikaishi Yasuhiro, Kanayama Masatoshi, Taira Akihiro, et al. (2019), "What is the best treatment strategy for primary spontaneous pneumothorax? A retrospective study", Annals of medicine and surgery (2012), 45, 98-101.

8. Yoshikawa Ryohei, Matsuura Natsumi, Igai Hitoshi, et al. (2021), "Uniportal approach as an alternative to the three-portal approach to videoassisted thoracic surgery for primary spontaneous pneumothorax", Journal of thoracic disease, 13(2), 927-934.

\section{NGHIÊN CỨU GIẢI PHẪU ĐÔ̂NG MACH CHẬU TRONG TRÊN HÌNH ẢNH CHỤP CẮT LỚP VI TÍNH 128 LỚP}

\section{TÓM TẮT}

Mục tiêu: Xác định nguyên ủy, kích thước và phân nhánh động mạch chậu trong trên hình ảnh chụp cắt lớp vi tính 128 lớp và phân tích ý nghĩa lâm sàng trong các trường hợp biến đổi giải phẫu động mạch. Phương pháp nghiên cứu: Mố tả tiến cứu và mồ tả hồi cứu từ 9/2017 đến 9/2018. Chọn mẫu: 128 tệp ảnh của 128 bệnh nhân với tiêu chuẩn lựa chọn là hình ảnh chụp động mạch chậu rõ nét và các tổn thương hẹp, tắc không quá $50 \%$ đường kính lòng động mạch. Kết quả $100 \%$ động mạch chậu trong được quan sát trên các tệp ảnh, 127 trường hợp quan sát thấy thân trước, thân sau đat $100 \%$, các nhánh mạch chỉ quan sát được từ $62 \%$ đến $100 \%$. Đường kính động mach chậu và thân chính là khoảng $3 \mathrm{~mm}$, các nhánh có đường kính nhỏ hơn $2 \mathrm{~mm}$. Các nhánh mach có tỷ lê biến đổi vị trí nguyên ủy từ $0.78 \%$ đến $6.82 \%$. Kết luận: Chụp cắt lớp vi tính 128 lớp là

\footnotetext{
${ }^{1}$ Trường Đai hoc Y Dước Thái Bình

Chịu trách nhiệm chính: Vũ Duy Tùng

Email: tunganatomy@gmail.com

Ngày nhận bài: 22/4/2021

Ngày phản biên khoa hoc: 19/5/2021

Ngày duyệt bài: 12/6/2021
}

Vũ Duy Tùng ${ }^{1}$, Nguyễn Thị Tho' ${ }^{1}$, Trần Thị Hằng ${ }^{1}$, Nguyễn Ngọc Trung ${ }^{1}$

phương tiên có khả năng thể hiện chính xác kích thước, hình thái và các biến đổi giải phấu động mạch.

Tư khóa: Giải phẫu động mạch chậu trong

\section{SUMMARY \\ ANATOMICAL RESEARCH OF ILIAC ARTERY ON THE IMAGE 128 MULTI SLICE COMPUTED TOMOGRAPHY}

Objective: Determination of the arises, size and branching of the pelvic arteries in the image on computed tomography of 128 grade and the analysis of clinical significance in cases of arterial anatomical changes. Research methods: Descriptive studies and retrospective studies from 9/2017 to 9/2018. Select Sample: 128 photo-files of 128 patients with the standard of choice are clear pelvic artery imaging and narrow lesions, which are not exceeding $50 \%$ of the arterial diameter. Results $100 \%$ of the pelvic artery is observed on the image files, 127 cases observed hull first, rear fuselage reached $100 \%$, the vascular branches were observed only from $62 \%$ to $100 \%$. The pelvic artery diameter and the main body are about $3 \mathrm{~mm}$, the branches are smaller in diameter than $2 \mathrm{~mm}$. The circuit branches have a arises variation ratio of $0.78 \%$ to $6.82 \%$. Conclusion: Computed tomography 128 grade is the means capable of 